REPERTÓRIO

LIVRE

\title{
A DESACELERAÇÃO E SUAS POTENCIALIDADES \\ CRIATIVAS NO TREINAMENTO CONTEMPLATIVO DO ARTISTA DA CENA
}

LA DESACELERACIÓN Y SUS POTENCIALIDADES CREATIVAS EN LA FORMACIÓN CONTEMPLATIVO DEL ARTISTA DE ESCENA

VANJA POTY SANDES GOMES MENEZES

JULIA ZIVIANI VITIELLO 


\section{RESUMO}

O artigo contempla as especificidades do exercício de Desaceleração como parte das investigações em andamento do Núcleo de Práticas Meditativas no Treinamento do Artista da Universidade do Estado do Amazonas. A vivência organiza-se a partir de influências das práticas da Companhia Club Noir, do budismo Shambhala e do Método Abramovic. Nesse sentido, o ator/performer se aproxima do "estado de trabalho" em seu treinamento por meio do aprimoramento psicofísico e da conexão com o ambiente na tentativa de dissolução de seus padrões habituais.

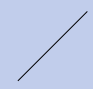

ABSTRACT

The article contemplates the specificities of the Deceleration exercise as part of the ongoing investigations of the Nucleus of Meditative Practices for Training Artists at the Amazonas State University. The experience is organized from the influences of the practices of Club Noir, Shambhala Buddhism and the Abramovic Method. In this sense, the actor/performer approaches the "working state" in his training through psychophysical enhancement and connection to the environment in an attempt to dissolve his usual patterns.

\section{RESUMEN}

El artículo contempla las especificidades del ejercicio de Desaceleración como parte de las investigaciones en marcha del Núcleo de Prácticas Meditativas en la Formación del Artista en la Universidade do Estado do Amazonas. La vivencia se organiza a partir de influencias de las prácticas de la compañía Club Noir, del budismo Shambhala y del Método Abramovic. A este respecto, el actor/performer se acerca al "estado de trabajo" en su formación mediante el perfeccionamiento psicofísico y de la conexión con el ambiente en la tentativa de disolución de sus estándares habituales. 


\section{A DESCOBERTA DA PRÁTICA}

\section{A DeSACELERAÇÃo É UM EXERCícIO CÊNICO viven-}

ciado por uma das autoras deste artigo em 2011, nos ensaios com a atriz Juliana Galdino na Companhia Club Noir, ${ }^{1}$ e que, desde 2015, segue trabalhando com o mesmo nos cursos de atuação que ministra e no projeto de extensão e pesquisa Núcleo de Práticas Meditativas no Treinamento do Artista da Universidade do Estado do Amazonas, misturando-o com outras inspirações, tanto artísticas, quanto contemplativas. Neste artigo, dissertamos sobre a vivência a partir das referências dos exercícios Desaceleração, caminhada lenta e meditação caminhando e do desejo de aliar meditação e caminhar no treinamento de artistas da cena.

A investigação dessa prática não se atém à simples aplicação dessas experiências citadas, mas estabelece um olhar antropofágico como caminho de pesquisa: deglutindo as inspirações e transformando-as em linguagem artística a partir das dinâmicas do processo criativo do treinamento. Para tal, a troca com os estudantes é sempre de grande valia para o percurso, pois a partir de seus relatos, questionamentos, dificuldades e acertos, podemos estabelecer um estado de permanente reorganização do experimento, em um movimento dialógico entre dúvidas e certezas rumo ao desconhecido.

1 Grupo de teatro sediado na cidade de São Paulo, fundado por Juliana Galdino e Roberto Alvim. A atriz descreve as práticas da companhia a partir dos procedimentos de imobilidade do ator, valorização das palavras e escuridão da cena, "trazendo à tona o inconsciente dos textos". (GALDINO, 2010, p. 117) Cabe ressaltar que, apesar da admiração pelo trabalho do grupo na época da vivência aqui descrita, as autoras deste artigo não coadunam de maneira algu ma com as atuais práticas e posicionamentos de seus integrantes. 
Na experiência artística com o Club Noir, a vivência se dava da seguinte maneira: ao chegarmos ao espaço de ensaio, tirávamos os sapatos e começávamos a caminhar bem devagar pelo tablado em silêncio, concentrados no espaço e atentos à música de fundo, que geralmente era calma e orquestrada. A prática durava em média 20 minutos - podendo tanto se estender por mais tempo nos ensaios, como ser de menor duração em dias de apresentação -, visava à concentração e o estabelecimento de um estado de prontidão distinto do habitual, e depois dela partíamos para o processo de criação do espetáculo propriamente dito.

Livia Piccolo (2013), pesquisadora do processo criativo da companhia, revela que a intenção do exercício está na percepção dos impulsos e tensões do artista que, na técnica, expurga vícios e excessos de atuação dando adeus à ansiedade e à sensação cotidiana de seu corpo. No percurso da caminhada, o ator transforma sua qualidade de presença conectando-se com o ambiente e consigo mesmo e, a partir deste estado desacelerado, está livre para dizer o texto desencobrindo e descascando suas palavras, pois cada uma delas “[...] é uma usina de energia e de sensações físicas, concretas". (PICCOLO, 2013, p. 89) Deste modo, na prática do grupo, a Desaceleração dá vazão para a descoberta das ressonâncias da dramaturgia textual no corpo-mente do artista.

Apesar de na época não entender muito bem a importância do exercício - vivenciando-o apenas como um aquecimento interessante para a prática cênica - a primeira experiência com a Desaceleração constituiu uma imagem geradora potente para o desenrolar desta prática em uma trajetória artística e pedagógica. Alguns anos depois, em março de 2015, a primeira autora deste artigo teve uma segunda oportunidade de vivenciar outra forma do exercício, chamada Slow Walking (Caminhada Lenta). Esta é parte integrante do Método Abramovic, desenvolvido pela performer sérvia Marina Abramovic, e que esteve presente na exposição Terra Comunal - Marina Abramovic + MAl em cartaz entre março e maio daquele ano no Sesc Pompeia/SP. O método é voltado para os fruidores das performances da artista que, a partir de uma série de atividades, se preparam para a apreciação das obras e também vivem a experiência performativa, em um processo de desconexão das distrações cotidianas. 
A Caminhada Lenta é um exercício de encontrar a imobilidade

através do movimento. Enquanto caminha lentamente, você não apenas abranda o corpo, a respiração e os pensamentos, mas todo o espaço ao seu redor. Os participantes atentam para cada ação de dar um passo: erguer o pé, movê-lo adiante, pousá-lo no chão e transferir o peso. Neste exercício, não há linha de chegada. Os participantes ficam à vontade para fazer uma ação que realizamos todo o dia sem pensar em um destino. (PEISINGER, 2016, p. 137)

Na Caminhada Lenta, os procedimentos são distintos da Desaceleração do Club Noir. Nesse contexto, antes de começar, guardamos nossos pertences e, somente se quisermos, tiramos os sapatos e outros acessórios; em seguida realizamos por 30 minutos uma série de exercícios chamada Aquecimento dos Sentidos, conduzida através de um vídeo² por Abramovic e Lynsey Peisinger, e que estimula a visão, a audição, o olfato, o paladar e o tato por meio de alongamentos e exercícios de respiração; depois recebemos fones isoladores de som e, em silêncio, guiados por arte-educadores treinados pela artista, somos divididos em quatro grupos e realizamos quatro tipos de atividades a partir das posturas fundamentais da meditação budista, cada uma com 30 minutos e em ordens diferentes para cada coletivo: em três delas - sentar, deitar e ficar em pé - nos relacionamos com esculturas criadas pela artista chamadas Objetos Transitórios e na restante caminhamos muito lentamente em linha reta, prestando atenção aos movimentos necessários para a marcha e em nossas reações ao exercício.

Com o tempo e em meio a estas práticas introspectivas, o caminhar se transforma em vivência meditativa. Peisinger (2016) relata que essa experiência é a sistematização e a síntese dos 40 anos da carreira artística de Abramovic, e que a simplicidade das ações propostas fomenta trocas de energia entre o público e o encontro com o silêncio e com o momento presente. Cabe lembrar que viver o instante presente é um conceito fundamental, tanto na performance, quanto nas tradições espirituais orientais. A artista sérvia, segundo Wescott (2015, p. 124), tem “fome por esoterismo" e, em sua trajetória, voltou-se para o misticismo budista, taoísta e hindu, de forma que suas ações performativas são influenciadas por estes universos. 
Desde 1979, a artista organiza uma oficina chamada Cleaning the House (Limpando a Casa) voltada para performers e estudantes de performance com duração de cinco a sete dias em meio à natureza. Nessa, exercícios realizados em Desaceleração - como caminhar, sentar, beber água, se vestir e escrever o próprio nome lentamente - são utilizados para a experimentação de novas formas de relação com o tempo e para treinar o autocontrole e a autopercepção dos artistas envolvidos. Ademais, a caminhada é empregada de diversas formas em práticas como pisar na terra e sentir o corpo, andar pela natureza por várias horas de olhos fechados ou abertos, caminhar em círculos, de costas, enxergando através de um espelho, entre outras variações.

Na vivência da oficina, o performer treina formatos intensivos da Caminhada Lenta do Método Abramovic - pensada para espectadores de suas obras, portanto mais suave - andando por quatro, oito, ou doze horas. Mary Richards (2010) declara que essas práticas são como rituais de purificação e preparação do corpo-mente do artista que, neste percurso, se abre para os fluxos de energia que fazem parte do processo criativo. Desse modo, as práticas de lentidão do workshop baseiamse na premissa de transformação de experiências aparentemente ordinárias em extraordinárias, exercitando a atenção para o corpo em movimento e sua relação com o espaço, muitas vezes alcançando estados contemplativos: como a Desaceleração é psicofísica, nosso ritmo interno também diminui.

Caminhar por longos períodos de tempo exercita potenciais de repetição que nos retiram da lógica cotidiana. Logo, andar não tem mais um propósito utilitário nesta prática, convertendo-se em uma cerimônia de ação contra o hábito. Na performance The Lovers: The Great Wall Walk (Os Amantes: A Caminhada pela Grande Muralha), de 1988, Abramovic caminha dois mil quilômetros ao longo de três meses pela Grande Muralha da China para encontrar seu parceiro criativo e de vida Ulay, que vinha do sentido oposto, e terminar a relação de doze anos. Mary Richards (2010, p. 99) recorda ainda que, no trajeto, “[...] a dor, a exaustão e o ato repetitivo de caminhar eram formas de deixar o corpo para trás para que um novo estado de consciência pudesse ser alcançado". Nas ações da artista sérvia, atingir e superar os limites físicos funciona como um portal para a criatividade. 
A terceira experiência com o exercício ocorreu poucos meses depois, no Centro Shambhala de Meditação São Paulo, por meio da prática da Meditação Caminhando. Nessa vivência, as indicações variam de acordo com o tipo de meditação desejada e com os níveis dos praticantes e seus respectivos tempos de aprendizado. De início, pode-se conhecer a forma considerada mais básica, a meditação Kinhin: a prática é realizada no Zen Budismo³ entre as sessões de Zazen - Meditação Sentada - e se caracteriza pelo alinhamento de ritmos entre caminhada e respiração, sendo considerada uma forma de meditação dinâmica. Deshimaru (2002) ressalta que o exercício se desenvolve a partir de uma atitude de dignidade e nobreza do praticante, que busca um apoio firme e silencioso nos pés, que influencia tanto em seu equilíbrio e tranquilidade no espaço de prática, quanto em suas vivências cotidianas.

O budismo Shambhala bebe da tradição japonesa em muitos de seus aspectos sobretudo devido à amizade de Chögyam Trungpa Rinpoche com o mestre Zen Shunryu Suzuki Roshi. Deste modo, tanto a forma básica de meditação - primeiro sentada, depois caminhando - quanto a disposição e cerimoniais das salas de meditação são abertamente influenciados pelo Zen budismo. Práticas como caligrafia, cerimônia do chá (Chado), arranjos de flores (Ikebana), poesia (Haiku), bem como meditação caminhando (Kinhin), arqueirismo (kyudo) e a prática de refeição contemplativa (oryoki) Zen também fazem parte do aprendizado.

Shunryu Suzuki reflete que a natureza da prática Zen encara a liberdade como um caminho para o encontro da serenidade em tudo que realizamos, não somente na inatividade do Zazen. Com o treinamento prosperamos pouco a pouco neste intento, aproximando-nos dele pela repetição constante das técnicas e pela despreocupação com uma linha de chegada inexistente. Podemos traçar um paralelo deste pensamento com a prática da Meditação Caminhando, que também não tem começo nem fim, ou mesmo algum alvo a ser atingido - apranihita: ausência de meta -, caminhamos pelo prazer de caminhar e “[...] simplesmente andamos devagar, de forma descontraída, mantendo um leve sorriso nos lábios”. (HANH, 1985, p. 9)

No aprendizado Shambhala a instrução básica para a vivência de Kinhin é a seguinte: após meditar por 20 minutos sentados com as pernas cruzadas e os olhos abertos, língua encostada no palato e a atenção na respiração, nos levantamos e 
caminhamos em círculo por 10 minutos em velocidade um pouco mais lenta que a rotineira, utilizando como pontos de referência os mesmos procedimentos que fizemos sentados, porém adicionando a atenção para a transferência de peso dos pés no chão na dinâmica da marcha. Completam a postura de meditação as mãos que se fecham na altura do plexo cardíaco, mão direita envolvendo a esquerda, como se estivéssemos segurando uma espada desembainhada imaginária durante a prática.

A princípio, esta soma de indicações requer atenção para ser assimilada, entretanto, o que importa é estabilizar o corpo-mente no momento presente e poder experienciar o agora, o instante. Repousamos na calma e deixamos nosso fluxo de pensamentos seguir como um rio, observando-os de longe e sem prender a atenção em nenhum deles. Caminhamos sem esforço ou julgamento, experimentando a sensação do sagrado em nossas ações. Sakyong Mípham, porém, declara que o início é duro e que, muitas vezes, somos escravos dos nossos pensamentos e dos nossos estados emocionais, de modo que a meditação gera tédio, preguiça e até mesmo ansiedade e desespero. Nesse contexto, Mípham (2013, p. 25) recorda um provérbio tibetano que enuncia que levar budismo para uma nova cultura é como “[...] cultivar uma flor sobre uma rocha”. Portanto, o treinamento meditativo, tal como a flor, necessita de condições adequadas para criar raízes e florescer.

Para Thich Nhat Hanh (1985) - monge vietnamita fundador do movimento Budismo Engajado -, a Meditação Caminhando se diferencia de nossas caminhadas rotineiras de deslocamento, pois, em sua prática, cada passo é uma reverência. Nos aterramos e, sem pressa, deixamos de lado ansiedades e preocupações, treinando o prazer de andar experienciando o momento presente, sem nos preocupar em chegar a lugar algum. Ao longo da prática, compreendemos que corpo e mente são dois aspectos da mesma realidade, de modo que, para o mestre, apesar da estabilidade da meditação sentada, o movimento faz desta forma de meditação a mais atraente para a união psicofísica do sujeito dentre as posturas descritas por Buda: em pé, sentada, deitada ou caminhando. 
Paz é todo passo.

O sol vermelho e brilhante é meu coração.

Toda flor sorri comigo.

Como é verde e fresco tudo que cresce.

Como é frio o vento que sopra.

Paz é todo passo.

Ele transforma em alegria o caminho interminável.

(HANH, 1985, p. 79)
No Cankama Sutta - aforismo sobre a Meditação Caminhando do tratado Anguttara Nikaya (29 a.C.), parte integrante dos Textos Canônicos Páli da tradição budista Theravada ${ }^{4}$-, andar com atenção e reverência traz cinco benefícios: capacidade de percorrer longas distâncias, ampliação do vigor, prevenção de doenças, boa digestão e concentração duradoura. Ajahn Nyanadhammo (2013), mestre Theravada da tradição Floresta, interpreta o sutra Cankama destacando que a resistência era fundamental na época de Buda que, para transmitir seus ensinamentos, teve que atravessar países a pé. Ademais, o vigor trazido pelo movimento da prática sobrepuja a sonolência da meditação sentada, de modo que seus estímulos sensoriais e o comprometimento físico fomentam o foco no instante presente.

Desde a primeira experiência em Shambhala, a primeira autora pode perceber que a prática de Kinhin Ihe atraía mais do que a de Zazen. Naquele momento sentia-se acolhida pelos passos do grupo na sala de meditação e pelos cheiros, texturas, sons e formas do ambiente: era como se seu corpo se inebriasse com a técnica, de modo que regressava para a meditação sentada irritada com a pressão da postura nos joelhos e sem vontade, o que foi se modificando com o tempo. Ainda influenciada pela vivência da Caminhada Lenta de Abramovic, compreendeu que a qualidade de presença desenvolvida na Meditação Caminhando seria de grande valia para o trabalho do ator/performer.
4 Após a morte do Buda Siddharta Gautama em 483 a.C, as diferenças na interpretação de seus ensinamentos deram origem a tradições diversas: a escola Theravada ou Hinayana (veículo estreito) é a mais antiga delas, datada de 330 a.C, considerada a "doutrina dos anciãos" e tem ênfase na disciplina meditativa do praticante e nos ensinamentos canônicos budistas, fundamentais para todas as visões, mas sem tolerar as revisões posteriores aos ensinamentos. As tradições Mahayana (grande veículo) e Vajrayana (veículo indestrutível) surgiram posteriormente - em 240 a.C. e 700 d.C. respectivamente - e têm como principal desígnio a compaixão amorosa voltada para a liberação do sofrimento de todos os seres. Entretanto, a escola Vajrayana - visão do budismo Shambhala e tibetano - emprega técnicas tântricas de controle de energia como meios hábeis (upaya) para a iluminação, bem como a orientação direta de um mestre/guru. 


\section{CONTORNANDO CRIATIVAMENTE ASDIFICULDADES}

Ao longo dos semestres nos quais essas práticas foram trabalhadas com os estudantes da Universidade do Estado do Amazonas, de tempos em tempos os coletivos reclamavam de dores na execução dos exercícios em sala e nas meditações extraclasse. Parte das turmas manifestava nos diários de bordo as sensações de peso excessivo, de falta de equilíbrio e coordenação motora na experiência da Desaceleração. Mípham (2013) observa que sentir dor durante a meditação - como pressão nos joelhos, tensão nos ombros e incômodos na coluna - é um obstáculo que nos impede de desfrutar a prática. Ele afirma que precisamos aprender a ser compreensivos conosco, de modo que vamos nos acostumando com as posturas - sentadas e em pé - de forma progressiva numa disciplina gentil.

Julia Ziviani Vitiello (2004), segunda autora deste artigo, recorda que cabe aos pés a função de nos conduzir pelos caminhos. São eles que, a despeito de serem considerados meramente utilitários em comparação aos devaneios intelectuais e às emoções, trazem suporte e equilíbrio metamorfoseados em porto seguro para um corpo que se estrutura no espaço e enfrenta os desafios do tato: atraindo e se opondo ao que o chão lhe oferece. Os pés são fonte do contato primeiro com as forças da natureza e, maleáveis, se adaptam às intempéries dos trajetos. Nas artes da cena, os pés precisam vencer as dificuldades estruturais que lhe são características para serem capazes de sustentar a presença cênica. Suas tensões podem desestabilizar a composição do corpo do artista e, se devidamente relaxados e com prontidão, convertem-se em uma passagem para fluxos energéticos distintos, provenientes tanto das “entranhas da terra” (VITIELLO, 2004, p. 46) quanto dos impulsos psicofísicos do ator/performer ao longo de seu processo criativo.

Raízes poderosas do corpo, seu suporte possibilita que a estrutura do torso se mantenha erguida, e que de seu tronco central surjam os braços, para se projetarem através do espaço e deixarem a cabeça livre para seguir em direção à luz, como fazem as 
A Meditação Caminhando, para Deshimaru (2002 apud BOVAY, 2005, p. 25), deve evocar o andar de um tigre, pois o animal desloca-se pela selva seguro de seu centro com equilíbrio e tranquilidade, de modo que “[...] o apoio do pé é firme e silencioso, como o passo de um ladrão". Refletindo sobre essa e sobre outras metáforas budistas para a compreensão do modo de caminhar da meditação, recordo dos procedimentos de composição física para treinamento do ator elaborados pela atriz italiana Roberta Carreri - do grupo Odin Teatret - que vivenciei entre 2009 e 2010 ao longo da pesquisa de campo do mestrado. Em diferentes etapas de sua trajetória, a artista concebeu diversas imagens para dar suporte para o ator encontrar a sua presença nos exercícios e para criar na relação com o espaço e com os seus companheiros de cena: na caminhada, muitas vezes realizada em slow motion, buscamos maneiras diferentes de mover o corpo no ambiente inspirados por imagens voltadas para a reverberação de associações físicas criativas no instante da cena.

A partir desta lembrança, foram trazidos para o final da instrução do exercício de Desaceleração metáforas para fomentar a criação dos coletivos trabalhados. Os artistas deviam pisar no chão como se estivessem tocando areia quente, ou ondas do mar, pregos, cubos de gelo, barro, fogo em brasa, dentre outras imagens que se modificavam de acordo com a temática das cenas ou com as necessidades de cada grupo. Por vezes, ficávamos por pouco tempo em uma imagem que se mostrava banal ou desinteressante, por outras, nos alongávamos em uma delas por diversos ensaios.

A experiência amplia o repertório de movimentos do ator/performer, trazendo consigo a continuidade da atenção dada aos pés na Desaceleração, pois, através dela, desenvolvemos o treinamento aprofundando os princípios investigados. Ao mesmo tempo, pode-se perceber que esta tentativa de sistematização de um treinamento se dava na organização e posterior recriação de procedimentos provenientes de diferentes tradições orientais e artistas inspiradores, inserindo neles novos elementos: transformando a prática proposta a partir de processos intuitivos ou de descobertas provenientes da repetição cotidiana de cada exercício.

Carreri (2011, p. 46), ao refletir acerca dos exercícios de acrobacia realizados nos primeiros anos do Odin Teatret, fantasia “o chão como um mestre Zen”, trazendo 
despertar e foco a cada queda. Desaceleramos e nos concentramos em como tocamos o chão, como ele se torna impulso para o deslocamento, como a caminhada decidida traz consigo a meditação e como é bonito poder construir matrizes de movimento buscando burlar criativamente esta estrutura aparentemente fixa, passando por cima do tédio inicial com o exercício. Depois de aprender a como se aterrar no solo, podemos brincar com o equilíbrio e logo retornar a ele.

Os impulsos metafóricos das imagens trazem aos pés jogos com a transferência de peso, com a lentidão e a aceleração, com a precisão dos detalhes, com as reverberações do estímulo através do corpo dos atores. Os pés investigam mudanças drásticas na ação ou alterações mínimas na intenção e na qualidade de energia do andar, reagindo às metáforas e tentando dialogar com os temas propostos: para Barba e Savarese (2012), eles são como um microcosmo potente para o ator e, portanto, precisam desenforma-se do molde dos sapatos apertados do dia a dia e desaprender a reprodução automática da maneira de caminhar cotidiana. São eles a base da atuação, quem decidem a configuração do corpo e suas nuances na cena e, em liberdade, devem buscar autodeformações criativas para a cena.

O diretor italiano recorda ainda da Caminhada Deslizante dos teatros Nô e Kyogen japoneses. Nessas duas linguagens artísticas, os pés deslizam lentamente sem nunca desgrudar do chão como se flutuassem, de modo que, nesses teatros, os artistas passam boa parte de sua trajetória treinando rakobi - esta técnica específica de caminhar - para o desenvolvimento de movimentos precisos e sutis. No palco desses teatros existe ainda uma passarela chamada hanamichi, ou caminho das flores, que divide a plateia ao meio, do palco até o fundo do teatro, e na qual os artistas entram e saem de cena executando esses diferentes tipos de andar com diferentes estilizações - “[...] é ao longo desse caminho que ganha forma a flor maravilhosa, o mais alto grau da arte do ator, segundo Zeami". (BARBA; SAVARESE, 2012, p. 225) 
parte da técnica cotidiana do corpo e, como tal, transforma-se em

um automatismo. O propósito do trabalho de composição com as pernas e pés é experimentar novas possibilidades [...] Para cada imagem, mudo a direção e a velocidade no espaço, buscando evitar as pausas, que são o resultado típico da defasagem produzida pela separação entre pensamento e ação. (CARRERI, 2011, p. 57)

Yoshi Oida (2001) afirma que, no teatro Nô, o movimento do corpo muitas vezes se restringe às pernas e aos pés. Os artistas desenvolvem uma aparência de serenidade, apesar do esforço, de modo que parecem sentados em seus próprios quadris, transmitindo tanto estabilidade quanto fluidez no caminhar. As pontas dos pés agarram o solo e o foco de energia se volta na reverberação do andar para o plexo solar - hara -, centro de força que sustenta o ator em sua ação. Enquanto se caminha, não se pensa em mais nada, pois o artista Nô se preocupa em simplesmente executar sua atividade. Em meio a este estado de prontidão, muitos temas e imagens podem florescer a cada dia, para atores e para espectadores.

\section{A DESCOBERTA DA BELEZA}

Caminhar, para Duarte Júnior (2000), é uma forma de vivenciar o sentimento da beleza que se relaciona com a percepção não pragmática do mundo e com a suspensão da visão rotineira da vida. Em contraposição à postura racionalista da civilização ocidental, a beleza não pode ser medida de forma objetiva, habitando a relação entre sujeito e objeto a partir da sensação do aqui e agora, antes mesmo da apreensão mediada pelos símbolos e pelos conceitos.

Amor, beleza, encantamento: quantas palavras proibidas em nosso rigoroso meio acadêmico, sempre cioso por definir seus objetos de estudo em termos de qualidades objetiváveis, isto é, mensuráveis - coisa que, definitivamente, não parece possível com estas três, dentre tantas outras aqui empregadas. Contudo, 
é preciso ousar; é preciso furar a crosta cientificista que vem tornando as reflexões acadêmicas impermeáveis à vida que realmente importa: aquela levada a efeito em nosso dia-a-dia, semeIhante às dos cientistas e luminares de conhecimentos parciais

- na verdade, a única vida que se tem, em que pese as abstrações conceituais com as quais se escrevem teorias, tratados e teses. A vida é exercida, antes de tudo, valendo-se desses saberes sensiveis e conhecimentos que o arrogante intelectual apressa-se logo em classificar como ‘não-científicos’ ou próprios do ‘senso comum', feito este não contivesse qualquer verdade ou validade prātica. (DUARTE JÚNIOR, 2000, p. 32-33)

O autor, a partir da investigação de Gilberto Kujawski (1988), assegura que caminhar é um dos fundamentos da humanidade e que se conecta diretamente com as nossas sensações e sentimentos. Porém, na organização das grandes cidades, o andar está reduzido a uma ação mecânica de transporte, sufocado entre a supervalorização dos carros e a busca do corpo perfeito nas esteiras das academias de ginástica. Não deambulamos mais descompromissados pelas ruas, nos sentimos inseguros e pouco atraídos pela sujeira e pela violência, além de perceber a atividade como perda de tempo.

Adriano Labucci sublinha o fato de a caminhada ser um exercício de liberdade e autonomia. Sua premissa se apoia na capacidade subversiva da prática como possibilidade de "[...] (r)e(s)xistência a motorização selvagem e desmedida" (LABUCCl, 2013, p. 9) das formas contemporâneas globalizadas. Nesse andamento, a experiência promove ações de insubordinação à cultura da velocidade e do consumo, distanciando-se das dinâmicas do mercado através da aceitação de sua lentidão intrínseca em comparação aos outros meios de transporte: não podemos andar com o objetivo de chegar rápido a algum lugar, é preciso contemplar e compreender o tempo das coisas do mundo, despertando os sentidos para o ambiente e para nossos estados de espírito, pois são eles que vão ditar o ritmo da marcha.

Não conseguimos caminhar carregando coisas em excesso, portanto a humildade é a qualidade intrínseca desta vivência. Através dela faz-se imperativa a escoIha entre ter e ser/agir, de modo que o caminhante precisa abandonar posses e 
apetrechos para poder seguir seu percurso. O autor afirma que a raiz etimológica da palavra humildade vem de humilitas (It.), termo que se relaciona abertamente com húmus, com a terra. Na tradição cristã, é o contato dos pés no chão - literal e metafórico - que nos torna humildes no reconhecimento de nossas limitações e nos auxilia no encontro com o deus e com a sua real natureza, o barro de que é constituído. Não é de se estranhar que o símbolo da soberba nesta tradição seja justamente um animal sem pernas, a cobra que se arrasta traiçoeira e orgulhosa desafiando os mandamentos desta divindade: “[...] humilitas é a condição imprescindivel para caminhar com Deus". (LABUCCI, 2013, p. 58)

Labucci recorda da máxima latina solvitur ambulando - caminhando se resolve. Ao longo da marcha, o prazer e a curiosidade afloram e, aos poucos, o estado contemplativo provocado por essa atividade dissolve as angústias do sujeito. As complicações e problemas relacionados ao lugar que o caminhante ocupa no mundo ficam em suspenso durante suas andanças e, a depender do tempo e do comprometimento com a jornada, podem resolver-se no processo de transformação do ser ao longo do caminho.

O autor lembra ainda do ensinamento budista de Sogyal Rinpoche, autor de $O$ livro tibetano do viver e do morrer, sobre o desapego e o desprendimento como práticas de vida que se dão a partir da compreensão da impermanência dos fenômenos. Nessa tradição, precisamos da meditação para nos desfazer do excesso de peso - material, emocional e mental - e estar presentes no aqui e agora. 0 desprendimento é como uma passagem para o vazio, uma abertura para estar no mundo com atenção e encanto. Porém, na dinâmica das grandes cidades, vivemos amedrontados e nos encerramos em condomínios fechados e shopping centers, de modo que a busca por segurança triunfa sobre a liberdade. Logo, também devido a desigualdades sociais diversas, a ação de flanar sem rumo pelo espaço da urbe transforma-se em estranheza, em uma atividade de "vagabundos" e de pessoas mal-intencionadas.

Rebecca Solnit (2016) corrobora com o pensamento do pesquisador italiano ao manifestar que a cultura do medo e a gentrificação fundaram um estilo arquitetônico hostil e violento - com muros, grades, cercas elétricas e espetos antimendigos nas calçadas - que desumaniza os sujeitos. Ao mesmo tempo, 
os espaços públicos ou se privatizam ou se abandonam e, para quem não tem acesso a estes paraísos artificiais de privilégio, não existem muitas possibilidades de engajamento com a prática do caminhar. Quando a apropriação destes espaços não acontece, as pessoas perdem também um pouco do conhecimento do próprio corpo, esquecendo-se de suas capacidades locomotoras imersos em uma lógica de produtividade na qual andar aberto para a apreciação se torna desperdício de tempo.

A autora afirma que esses acontecimentos incitam a opressão do corpo vivo em atividade. Distante de utilitarismos, o ato de caminhar livremente é fonte de conhecimento e observação de si e do mundo: serena as angústias psicofísicas e desencadeia o filosofar, em coletivo associa-se aos ritos e aos movimentos sociais de resistência, subverte a separação entre corpo e mente cartesiana e, finalmente, passa a ser entendido como arte a partir dos experimentos performativos da década de 60 do século passado, ativando experiências da beleza em artistas e fruidores. $\mathrm{O}$ aqui e agora da marcha excita nossos sentidos por meio da ativação de signos não verbais constantes, como cores, cheiros, imagens e texturas. Nosso corpo movimenta-se encarnando e congregando saberes, revelando o “[...] parentesco consanguíneo do saber com o sabor: saber implica em saborear elementos do mundo e incorporá-los a nós (ou seja, trazê-los ao corpo, para que dele passem a fazer parte)". (DUARTE JÚNIOR, 2000, p. 133)

Fayga Ostrower (2014) preocupa-se com a constante alienação dos indivíduos e afirma que o afastamento de si mesmo separa o ser de seu potencial criativo. Para a artista, nos desintegramos a cada dia por conta do bombardeio de informações e deveres a que somos submetidos para sobreviver. Em meio à crescente aceleração do ritmo do viver, a maioria das pessoas não consegue perceber o mundo de modo significativo e, por consequência, não estabelece relações entre seus múltiplos elementos: ou seja, não ativa a própria sensibilidade e não se dispõe a criar.

Nesse sentido, o fazer artístico tem como principal finalidade a intensificação da vida, “[...] ampliando em nós a experiência de vitalidade”. (OSTROWER, 2014, p. 28) Para isso, devemos buscar condições de existência que promovam nossas potencialidades em um processo de renovação espiritual e de conscientização interior. A noção espiritual levantada por Ostrower relaciona-se com a sustentação 
de um estado de tensão psíquica durante o processo criativo do artista, como uma capacidade de engajamento para manter um nível profundo de sensibilidade. Criar é, portanto, um desassossego, um caminho para a comunicação com o meio e com a nossa individualidade que amplia a consciência de si e do mundo, assim como a prática contemplativa da Desaceleração no treinamento.

\section{CONSIDERAÇÕES}

A cada experimento com os grupos de estudantes na universidade, fica mais claro que a Desaceleração, além de conectar o ator consigo mesmo, aquecer o corpo e fomentar uma atmosfera propícia para a prática artística, também estimula os sentidos e a criação, tornando-se parte dela e incitando impulsos motivadores para o artista. No treinamento, observamos que a ação de caminhar traz consigo um estado de dilatação psicofísica para o ator. Essa zona de intensidade se assemelha com a noção de presença autêntica cunhada por Chögyam Trungpa (2013). O mestre recorda que o termo é derivado da palavra tibetana wangthang, que significa “campo de poder". Nesse sentido, através da meditação, o praticante pode irradiar uma qualidade de expansão psicofísica no espaço, assim como o artista por meio do treinamento pois, em cena, muitas vezes esta potência aparece como um vislumbre e, para saber como sustentá-la, é necessário constância e disciplina.

No contexto desta investigação, o processo de Desaceleração trabalha a dissolução de expectativas e temores do performer para que, por meio da repetição da ação e do desenvolvimento da atenção plena, este acesse o estado de trabalho - a presença psicofísica dilatada necessária para a prática artística. Exercitamos a serenidade da mente discursiva a partir da precisão da técnica: concentrando-nos no fluxo respiratório, no toque da sola dos pés no chão e na postura, nos distanciando do ego e de seus múltiplos filtros que embaraçam nossa percepção direta dos fenômenos. Portanto, a atenção plena é o estado de 
permanência da tranquilidade da consciência desvinculada da construção social de uma identidade imutável.

Ponderamos que, em um primeiro momento, a Desaceleração traz para o artista da cena a necessidade do desenvolvimento da precisão vigilante de suas ações e pensamentos para que o corpo-mente atinja estabilidade e possa repousar no agora. De início, para cessar as distrações, as fantasias e o discurso do ator/performer, o treinamento requer o afastamento do cotidiano para “[...] recolher a luz dispersa e focá-la em direção a nós mesmos". (MÍPHAM, 2013, p. 74) A vivência traz consigo doses homeopáticas de vivências incondicionadas: neste estado, reconhecemos nossas potências e transformamos a visão meramente conceitual que temos das coisas, percebendo o quanto estamos limitados às emoções e aos pensamentos no nosso dia a dia e em nossa zona de conforto.

A partir deste estado de trabalho, relaxamos na técnica para apreciar o nosso entorno de forma panorâmica, desenvolvendo um campo de força para, a partir dele, experienciamos o cosmos imersos em um mar de sinestesias. Nos movemos livremente pelo espaço, presentes em nossa própria carne e sentindo os batimentos cardíacos, o suor escorrendo nas costas, os sons da sala de ensaio, os cheiros e o gosto na boca, as cores, o toque dos pés no chão e as pessoas ao nosso redor.

\section{REFERÊNCIAS}

BARBA, Eugênio; SAVARESE, Nicola. A arte secreta do ator: dicionário de antropologia teatral. São Paulo: É Realizações, 2012.

CARRERI, Roberta. Rastros: treinamento e história de uma atriz do Odin Teatret. São Paulo: Perspectiva, 2011.

DESHIMARU, Taisen. Zen verdadero: Introducción al Shobogenzo. Barcelona: Kairós, 2002.

DUARTE JÚNIOR, João Francisco. O sentido dos sentidos: a educação (do) Sensível. 2000. 233 f. Tese (Doutorado em Educação) - Faculdade de Educação, Universidade Estadual de Campinas, Campinas, SP, 2000. 
GALDINO, Juliana. Os atores em tríptico (Impressões dos 10 atores da companhia CLUB NOIR acerca do processo de construção do espetáculo). Sala Preta, São Paulo, v. 10, p. 117-121, nov. 2010 .

HANH, Thich Nhat. Meditação andando. Petrópolis, RJ: Vozes, 1985.

KUJAWSKI, Gilberto de Mello. A crise do século XX. São Paulo: Ed. Ática, 1988.

LABUCCI, Adriano. Caminhar, uma revolução. São Paulo: Editora Martins Fontes, 2013.

MÍPHAM, Sákyong. Convertir la mente en nuestra aliada. Bilbao: Desclée de Brouwer, 2013.

NYANADHAMMO, Ajahn. Meditação a andar. Fonte Boa dos Nabos: Publicações Sumedhārāma, 2018. Disponivel em: https://forestsangha.org/teachings/books/meditacao-aandar?language=Portugu\%C3\%Aas. Acesso em: 10 abr. 2019.

OIDA, Yoshi. O ator invisivel. Com colaboração de Lorna Marshall. Prefácio de Peter Brook. São Paulo: Beca Produções Culturais, 2001.

OSTROWER, Fayga. Criatividade e processos de criação. Petrópolis, RJ: Vozes, 2014.

PEISINGER, Lynsey. O Método Abramović. In: REBOUÇAS; VOLZ (org.). Terra Comunal - Marina Abramović + MAI. São Paulo: Editora SESC, 2016. p. 135-159.

PICCOLO, Lívia. No interior da palavra: reflexões sobre voz, som e silêncio a partir da Cia. Club Noir. 2013. 120 f. Dissertação (Mestrado em Artes Cênicas) - Escola de Comunicação e Artes, Universidade de São Paulo, São Paulo, 2013.

RICHARDS, Mary E. Marina Abramović. Volume 9 - Routledge performance practitioners. New York: Routledge, 2010.

SOLNIT, Rebeca. A história do caminhar. São Paulo: Editora Martins Fontes, 2016.

TRUNGPA, Chögyam. Shambhala: a trilha sagrada do guerreiro. São Paulo: Cultrix, 2013.

VITIELLO, Julia Z. Dança: memória nos corpos cênicos. 2004. 184 f. Tese (Doutorado em

Educação) - Faculdade de Educação, Universidade Estadual de Campinas, Campinas, SP, 2004.

WATTS, Alan. O que é Zen? Campinas, SP: Verus, 2009.

WESCOTT, James. Quando Marina Abramović morrer: uma biografia. São Paulo: Editora Sesc, 2015. 
Vanja Poty Sandes Gomes Menezes: é professora de atuação do Curso de Teatro da Universidade do Estado do Amazonas, doutora em Artes da Cena (IA/Unicamp). Autora de A cena e o sonho: poéticas rituais de criação na obra do Odin Teatret (2015). Líder do grupo de pesquisa Vazio: entre, além e através dos treinamentos e das performatividades da cena, e do NUPRAMTA: Núcleo de Práticas Meditativas no Treinamento do Artista. poty.vanja@gmail.com

Julia Ziviani Vitiello: é professora titular do Departamento de Artes do Corpo do Instituto de Artes da Universidade Estadual de Campinas (Unicamp) doutora em Educação pela Unicamp. Orientadora da tese Desacelerando ou uma Ode ao Sol, ao caminhar e às borboletas: práticas de meditação e yoga no treinamento do artista da cena (2018), que deu origem a este artigo. ziviani.julia@gmail.com 